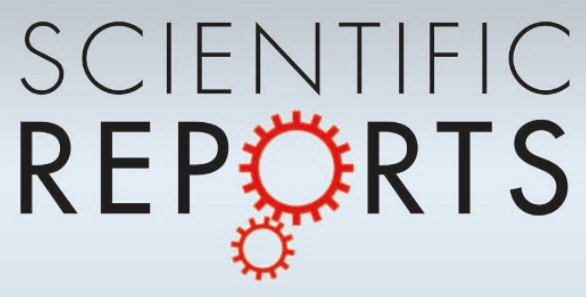

OPEN

SUBJECT AREAS:

ZOOLOGY

CONSERVATION

ECOLOGICAL EPIDEMIOLOGY

Received

7 August 2013

Accepted

31 December 2013

Published

23 January 2014

Correspondence and requests for materials should be addressed to

J.J. (johanna.judge@

ahvla.gsi.gov.uk) or

R.A.M. (r.mcdonald@ exeter.ac.uk)

\title{
Density and abundance of badger social groups in England and Wales in 2011-2013
}

\author{
Johanna Judge', Gavin J. Wilson', Roy Macarthur², Richard J. Delahay' \& Robbie A. McDonald ${ }^{3}$
}

\begin{abstract}
${ }^{1}$ National Wildlife Management Centre, Animal Health and Veterinary Laboratories Agency, Woodchester Park, Stonehouse GL10 3UJ, UK, ${ }^{2}$ Food and Environment Research Agency, Sand Hutton, York YO4 1 1LZ, UK, ${ }^{3}$ Environment and Sustainability Institute, University of Exeter, Penryn, Cornwall, TR 10 9EZ, UK.
\end{abstract}

In the United Kingdom, European badgers Meles meles are a protected species and an important wildlife reservoir of bovine tuberculosis. We conducted a survey of badger dens (main setts) in $16141 \mathrm{~km}$ squares across England and Wales, between November 2011 and March 2013. Using main setts as a proxy for badger social groups, the estimated mean density of badger social groups in England and Wales was $0.485 \mathrm{~km}^{-2}$ (95\% confidence interval 0.449-0.521) and the estimated abundance of social groups was $71,600(66,400-$ $76,900)$. In the 25 years since the first survey in 1985-88, the annual rate of increase in the estimated number of badger social groups was 2.6\% (2.2-2.9\%), equating to an $88 \%(70-105 \%)$ increase across England and Wales. In England, we estimate there has been an increase of 103\% (83-123\%) in badger social groups, while in Wales there has been little change $(-25$ to $+49 \%)$.

- uropean badgers Meles meles are the focus of intense public debate in the United Kingdom. They are an iconic wildlife species in British society ${ }^{1}$ and are protected under U.K. and European legislation. In the U.K. and Republic of Ireland they are also a reservoir of Mycobacterium bovis, the causative agent of tuberculosis in badgers and cattle ${ }^{2}$. Bovine tuberculosis (TB) is a major animal health challenge in the U.K. that results in substantial financial losses to taxpayers and farmers ${ }^{3}$. Control of TB in cattle is complicated by the reservoir of infection in badgers. Badger culling as a means of disease control is controversial, because of public concerns for badger conservation and welfare and because of the complex outcomes of culling for disease in badgers and cattle ${ }^{4-7}$.

Across much of the U.K. badgers live in social group territories with several shared dens, known as setts ${ }^{8}$. Because they are a protected species, any disturbance to individuals or their setts, requires a license from government ${ }^{9}$, which must take into account their conservation and population status. The size of the badger population in England and Wales is the subject of high levels of public interest and wide-ranging speculation because of the lack of recent data ${ }^{10}$. Therefore, it is important for the public and governments to have robust knowledge of badger populations.

There have been two surveys of badger populations in Great Britain that employed the same methodology, consisting of field surveys for badger setts in a random sample of $1 \mathrm{~km}$ squares, stratified by the U.K. landscape classification (Land Class Group) system ${ }^{11}$. The first survey in $1985-88^{12}$ covered $24551 \mathrm{~km}$ squares and the second, in $1994-97^{13}$, resurveyed 2271 of these and an additional 307 squares. To relate their findings to numbers of social groups, both surveys assumed that one main sett was present in each social group territory ${ }^{12,13}$. The number of badger social groups in Great Britain was estimated to have increased from 41,894 (95\% confidence intervals $37,490-46,298)$ in the 1980 s to $50,241(45,914-54,568)$ in the 1990 s, i.e. an increase of $24 \%{ }^{12,13}$. There has been no survey of badger setts over the whole of Great Britain since the 1990s. A survey of Scotland was conducted in $2007-09^{14}$ and resulted in an estimate of 7,300-11,200 social groups, with central estimates of 8955 or 9370 , depending on the statistical assumptions made. Although this survey was not directly comparable to the earlier surveys, the authors concluded that their data suggested there could have been a substantial increase in the number of setts in Scotland since the 1990s but could not rule out this difference arising from differences in survey protocols ${ }^{14}$, underlining the importance of applying consistent methodology between surveys. In Northern Ireland, which also forms part of the U.K., badger surveys employing the same methodology were conducted in $1990-93^{15}$, and again in $2007-08^{16}$, the latter of which estimated the presence of 7,600 $(6,200-9,000)$ social groups, with no significant change in abundance between the two surveys. 
We conducted a survey of badger setts in England and Wales in 2011-13 and report the results of our estimates of the abundance of badger social groups. We compare these to earlier surveys and compile our results with the published outcomes of the most recent surveys of Scotland and Northern Ireland, to derive estimates of the abundance of badger social groups in Great Britain and the United Kingdom.

While badger sett surveys are well suited to estimating the abundance of social groups, on their own they are limited in their suitability for estimating populations of individual animals ${ }^{17}$. This is principally because sett characteristics are a poor predictor of badger numbers ${ }^{18}$, and group size can vary widely ${ }^{19}$ making it difficult to obtain a representative mean across an adequate sample. We are currently undertaking work to estimate group sizes across a large sample of setts in order to estimate badger population size.

\section{Results}

Survey coverage. We surveyed $17021 \mathrm{~km}$ squares. Of these, 1614 (95\%) squares were included in our analyses. The remaining 88 squares were removed, because in each case access to land was denied for $>50 \%$ of the area. The 1614 squares comprised 1411 squares in England and 203 squares in Wales, leading to survey coverage of $1330 \mathrm{~km}^{2}$ (1.0\% of land area) in England and $184 \mathrm{~km}^{2}$ $(0.9 \%)$ in Wales.

Badger sett distribution. We estimate that active main badger setts are present in $34.4 \%$ (95\% confidence intervals $32.2-36.7 \%$ ) of rural $1 \mathrm{~km}$ squares in England and Wales and that active setts of any type are present in $56.3 \%$ (95\% confidence intervals $53.9-58.6 \%$ ) of rural $1 \mathrm{~km}$ squares.

This represents an increase of $14.4 \%$ points ( $95 \%$ confidence intervals $11.5-17.3 \%$, i.e. an increase from $20.0 \%$ to $34.4 \%$ ) since the 1985-88 survey in the proportion of $1 \mathrm{~km}$ squares that contain a main sett and $21.2 \%$ points (17.8-24.5, i.e. an increase from $35.1 \%$ to $56.3 \%)$ in the proportion that contain any badger sett.

Badger sett density and abundance. The estimated mean density of main setts in rural England and Wales was $0.485 \mathrm{~km}^{-2}(0.449-$ 0.521). The density of badger setts varied among Land Class Groups (Table 1). The total number of main badger setts, and hence the number of social groups, in rural England and Wales in 2011-13 was estimated to be $71,600(66,300-76,900)$.

Combining our survey results with the 2007-09 survey of Scotland ${ }^{14}$, and assuming no change in Scotland since then, results in an estimate of $81,000(75,400-86,600)$ social groups in Great Britain. Combining this estimate for Great Britain with the 2007-08 survey of Northern Ireland ${ }^{16}$, again assuming no change in Northern Ireland since then, results in an estimate of 88,600 (82,900-94,400) social groups in the United Kingdom.

Changes in badger sett density and abundance. Comparing the results of the present survey with the first survey indicates that the estimated density of main setts in England and Wales is now 88\% (70-105\%) greater than in 1985-88, suggesting an estimated average annual rate of increase of approximately $2.6 \%$ (2.2-2.9\%). Estimated annual rates of increase between 1985-88 and 1994-97 (0.6-3.5\%) and between 1994-97 and the present survey (2.1-3.3\%) did not differ significantly $(\mathrm{p}=0.21$, assuming a single rate exponential in each time interval). In order to realize this increase, the abundance of badger social groups in England and Wales is likely to have increased by $27,000-40,000$ over the 25 years between the median dates of the first and the most recent surveys. The pattern of change in estimated social group density differed between England and Wales. Since $1985-88$, the estimated number of social groups has increased by 103\% (83-123\%) in England. By contrast estimated sett densities have remained approximately constant in Wales (change of between -25 and $+49 \%$ ) (Table 1, Figure 1 ).

Changes in the estimated density of main setts varied among Land Class Groups (LCGs) (Table 1, Figure 2). Increases were observed in the more widespread LCGs (Arable 1, Arable 2, Pastoral 4, Pastoral 5 and Marginal Upland 6). There may also have been an increase in LCG Arable 3, but the large relative uncertainty associated with the estimated change meant that a decline could not be ruled out (Figure 2). The small area of LCG Arable 3 meant the effect of this uncertainty on the estimation of change in overall numbers of main setts is small.

\section{Discussion}

A robust estimate of the current badger population in England and Wales is not yet available because assessment of variation in the number of individual badgers in social groups is ongoing. However, there was no primary assessment of social group size in either of the previous surveys ${ }^{12,13}$. Therefore, while we can infer change in the abundance of social groups, we cannot ever know whether social group sizes have increased, remained constant or declined between surveys. A measure of social group abundance may nonetheless be at least as useful as a total population estimate, despite the intuitive appeal of the latter, because a) it is less likely to vary at fine temporal scales, i.e. numbers per group may vary between years but numbers of social groups may be more $\left.\operatorname{stable}^{20}, b\right)$ it is epidemiologically informative because of the importance of social structure to TB transmission in badgers ${ }^{7}$ and c) because assessments

Table 1 | Results of a badger sett survey in England and Wales in 201 1-13. Land Class Groups (LCG) are described in Supplementary Table 1 and their distribution is shown in Supplementary Figure 1. Data from 1985-88 and 1994-97 are from earlier surveys. Small discrepancies may arise between strata totals as a result of within-stratum variation and rounding

\begin{tabular}{|c|c|c|c|c|c|c|c|c|c|c|}
\hline \multirow{2}{*}{ Area/Stratum } & \multirow{2}{*}{$N$ squares } & \multirow[t]{2}{*}{$\begin{array}{l}\text { Survey area } \\
\left(\mathrm{km}^{2}\right)\end{array}$} & \multirow[t]{2}{*}{$\begin{array}{l}N \text { squares } \\
\text { with main } \\
\text { setts }\end{array}$} & \multirow{2}{*}{$\begin{array}{c}N \text { main } \\
\text { setts }\end{array}$} & \multirow{2}{*}{\multicolumn{2}{|c|}{$\begin{array}{l}\text { Density of main setts } \\
\mathrm{km}^{-2} \pm 95 \% \\
\text { Confidence Interval }\end{array}$}} & \multicolumn{4}{|c|}{ Abundance of main setts $\pm 95 \%$ Confidence Interval } \\
\hline & & & & & & & \multicolumn{2}{|c|}{$2011-13$} & 1994-97 & $1985-88$ \\
\hline England and Wales & 1614 & 151 & 612 & 82 & 0.485 & \pm 0 . & 71600 & \pm 5300 & $46100 \pm 4300$ & $38100 \pm 4100$ \\
\hline Eng & & & & 74 & & & & & Not esti & $00 \pm$ \\
\hline Wa & 20 & 18 & 61 & 77 & 0 & \pm 0 & 73 & \pm 1 & Not estimated & $6600 \pm 1600$ \\
\hline LCC & 1 & $1 \varepsilon$ & & & & & & & $6300 \pm$ & $6400 \pm 1$ \\
\hline & 43 & 40 & & & & & & & $11200 \pm 1$ & $8900 \pm$ \\
\hline LCG & 27 & 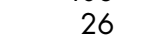 & 7 & 9 & 0 & \pm 0 & 1200 & \pm 9 & $300 \pm 1100$ & $590 \pm 450$ \\
\hline & 52 & $4 \varepsilon$ & 26 & 36 & & & 24000 & & $15700 \pm 2$ & $14300 \pm 2800$ \\
\hline LCG & 22 & 20 & 60 & 7 & 0.3 & \pm 0. & 8800 & \pm 2 & $7700 \pm 1800$ & $5000 \pm 1500$ \\
\hline LCG & 18 & 17 & 42 & 53 & & \pm 0 . & 6500 & & $4200 \pm 1600$ & $2700 \pm 1100$ \\
\hline LCG Upland 7 & 29 & 29 & 0 & 0 & 0.000 & NA & 0 & NA & $530 \pm 560$ & $100 \pm 200$ \\
\hline
\end{tabular}




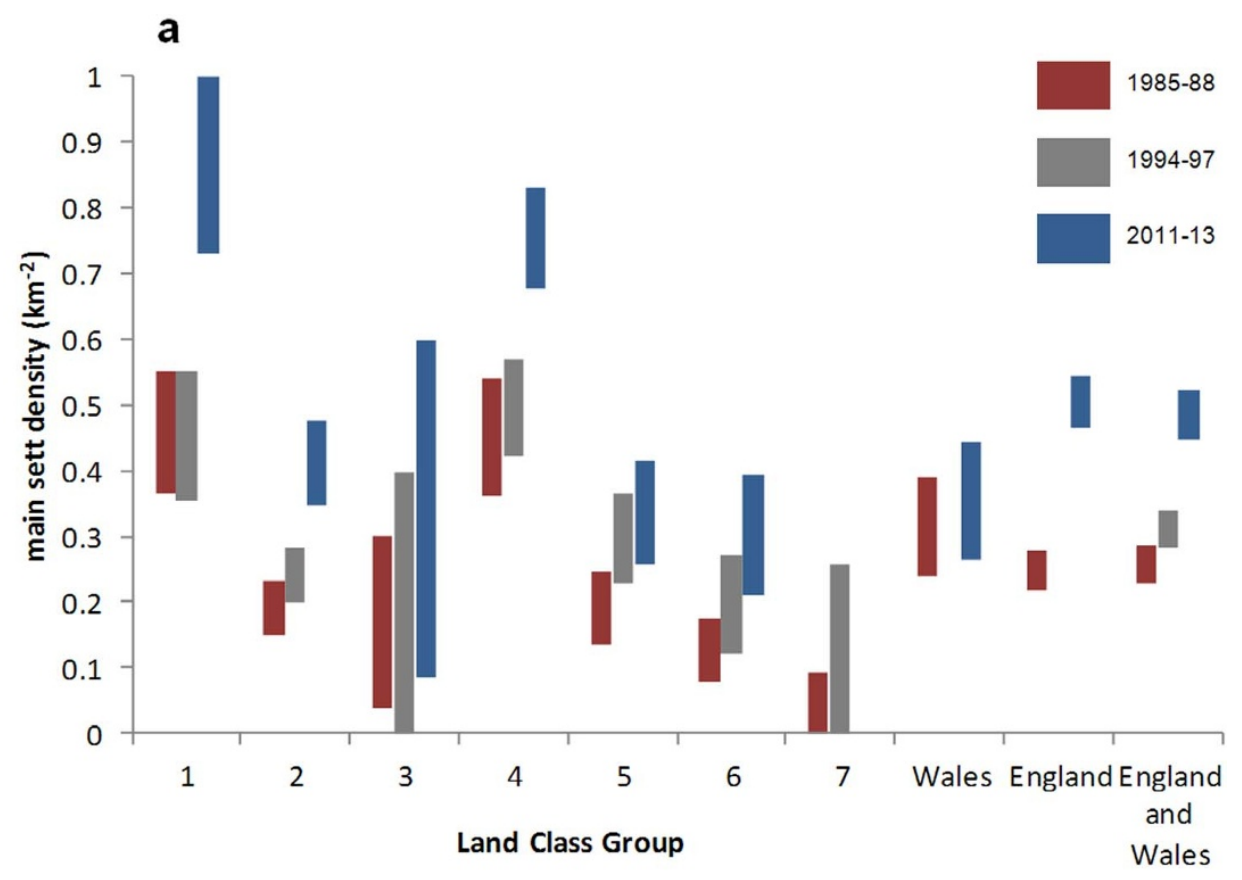

b

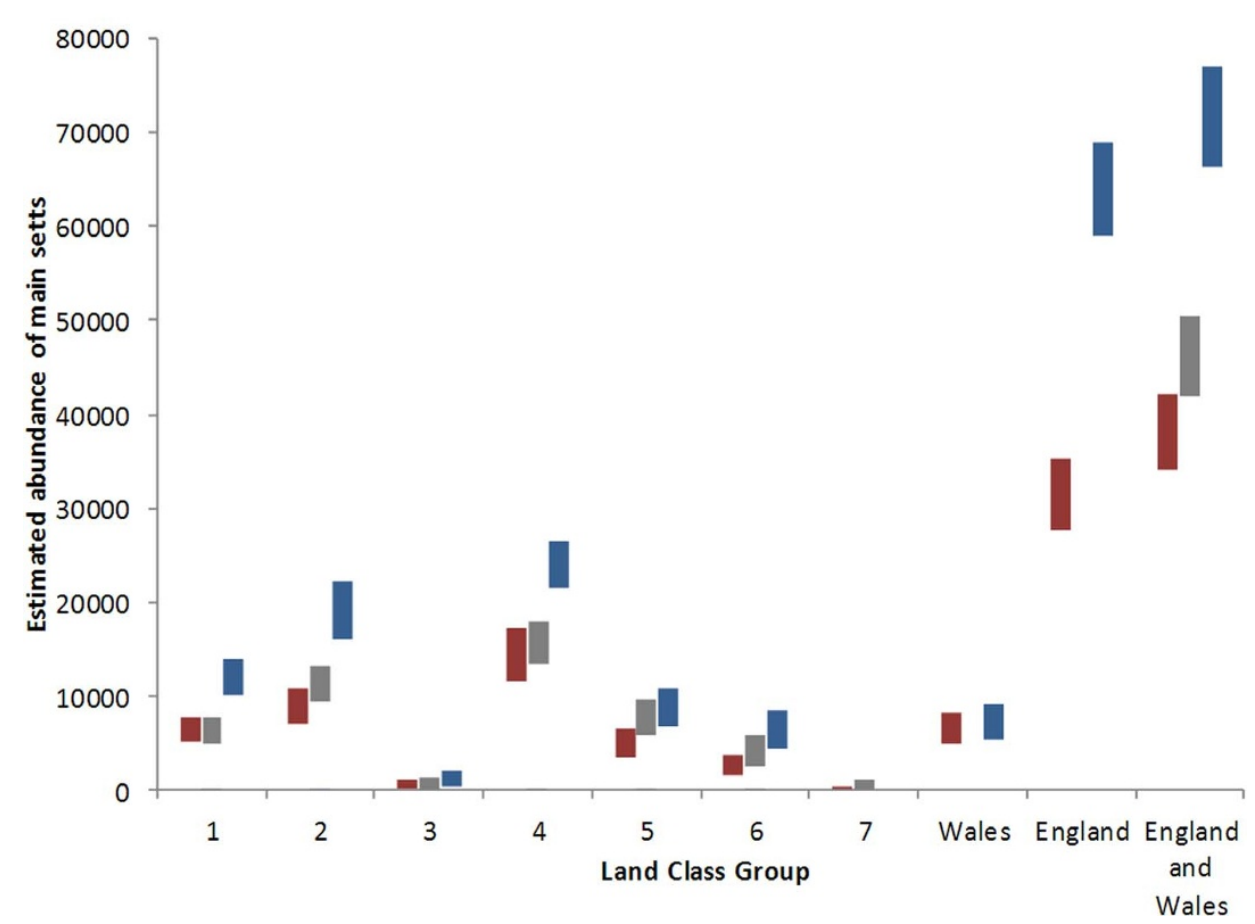

Figure 1 Estimates of badger main sett (a) density and (b) abundance in England and Wales and by Land Class Group in three surveys. Shaded blocks indicate $95 \%$ confidence intervals for means. No main setts were identified in LCG 7 in the 2011-13 survey.

of conservation and other management actions are often made at a social group level ${ }^{9}$.

Although our protocol was similar to previous surveys in most respects, a large proportion of squares in the earlier studies were surveyed by experienced volunteers (73\% in 1985-88 and $68 \%$ in 1994-97) as opposed to trained professional surveyors, as in our survey. Clearly, we cannot retrospectively assess the quality of earlier surveys, but both the 1980s and 1990s surveys also used professionals to conduct a proportion of their surveys and so they were able to test surveyor reliability in identifying sett types. They found that fewest problems arose with the classification of main setts from other sett types. They also found no consistent patterns in sett encounter rates among volunteers and professionals and so were content to pool data from all surveyors for analysis ${ }^{12,13}$. While we are confident in our professional estimates of current main sett abundance, it remains a possibility that previous, partly amateur, surveys did not identify setts with the same success or classify setts in the same way as this survey, potentially leading to some additional error in our estimates of change between surveys. Nonetheless, our survey represents a robust, national-scale assessment of badger social group abundance 

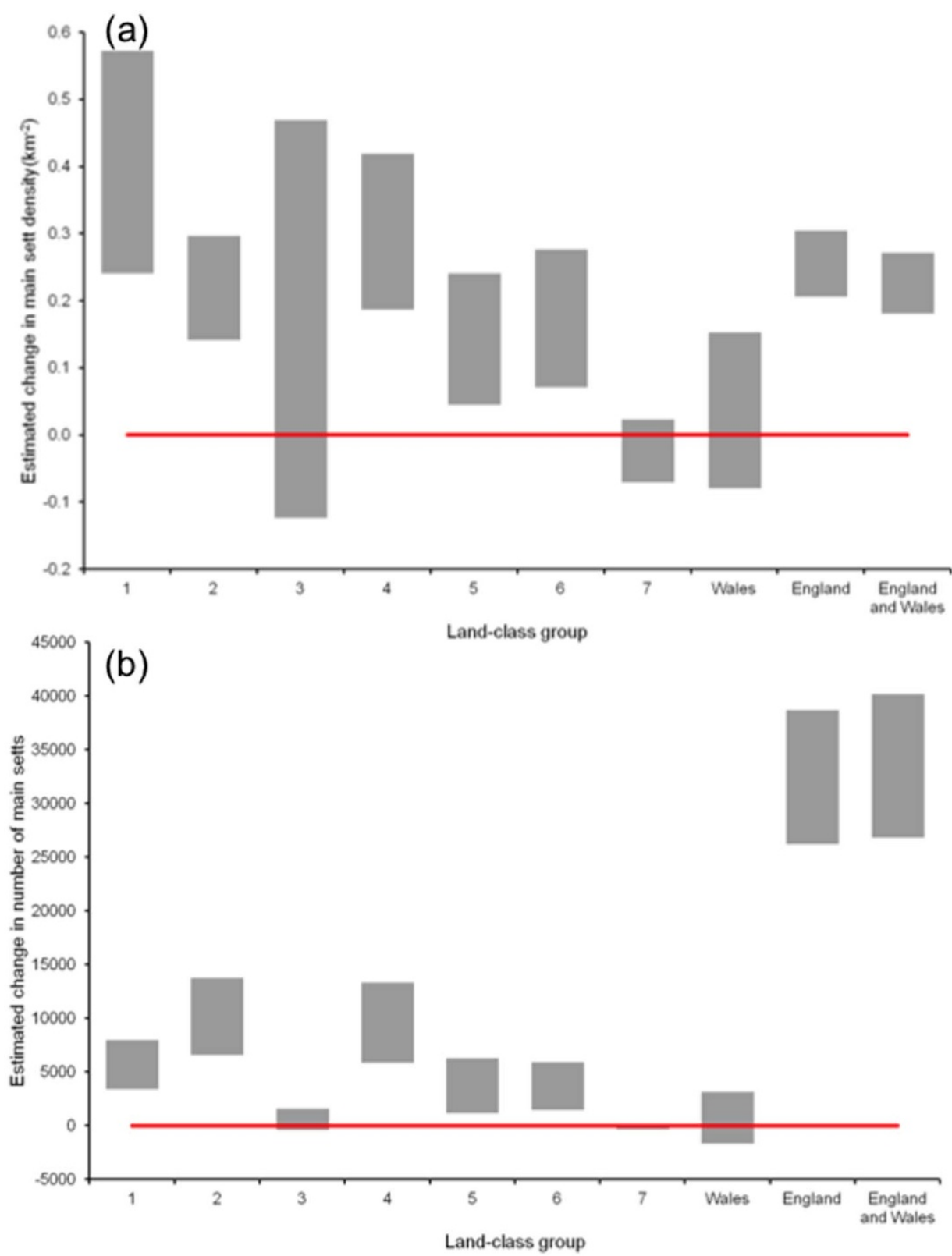

Figure 2 Estimates of changes in badger main sett (a) density and (b) abundance in England and Wales and by Land Class Group between 1985-88 and 2011-13. Shaded blocks indicate 95\% confidence intervals for estimates of change. Where these do not overlap the red line, indicating no change, the change is considered statistically significant.

in 2013. It is comparable in approach to those based on sett surveys conducted in 1985-88 and 1994-97 and so is the best, and probably only, basis on which to assess badger population change at the national scale.

This survey highlights a general increase in estimates of badger social group density/abundance, with some regional variation. The marked increase in estimated main sett density in LCG Arable 1, which is found across much of south central England, is particularly noteworthy because density in this landscape did not appear to have changed between the $1980 \mathrm{~s}$ and $1990 \mathrm{~s}^{13}$. The difference in the estimated magnitude of change in England and Wales suggests that in addition to landscape effects, there are further regional effects on population change.

At the landscape scale, there is a general association between the density of badgers and the density of setts ${ }^{18}$. The long term increase in the estimated abundance of badger main setts reported here is likely to indicate an increase in badger numbers though the magnitude of that increase cannot be determined, as the general relationship between social group abundance and population size has not been established. Long term badger population monitoring at a $\sim 7 \mathrm{~km}^{2}$ site at Woodchester Park in Gloucestershire, where the density of social groups has varied from 3-4 $\mathrm{km}^{-2}$, showed that the number of groups remained relatively constant over time, while badger population size more than doubled from 1982 to a peak in 1999, and subsequently declined to $2005^{20}$. In a $22 \mathrm{~km}^{2}$ study area in Sussex the number of main setts more than doubled within a 20 year period, though a proportion of this increase was due to large territories being subdivided $^{21,22}$. At Wytham Woods in Oxfordshire, a long-term study of an undisturbed population showed doubling in population size between 1987 and 1996, followed by a decline in the late 1990s and further increases thereafter ${ }^{23}$. Thus, there is ample scope for badger populations to vary over time, because of changes in both the abundance and size of social groups. Furthermore, owing to the long intervals between the national sett surveys, we cannot use these 


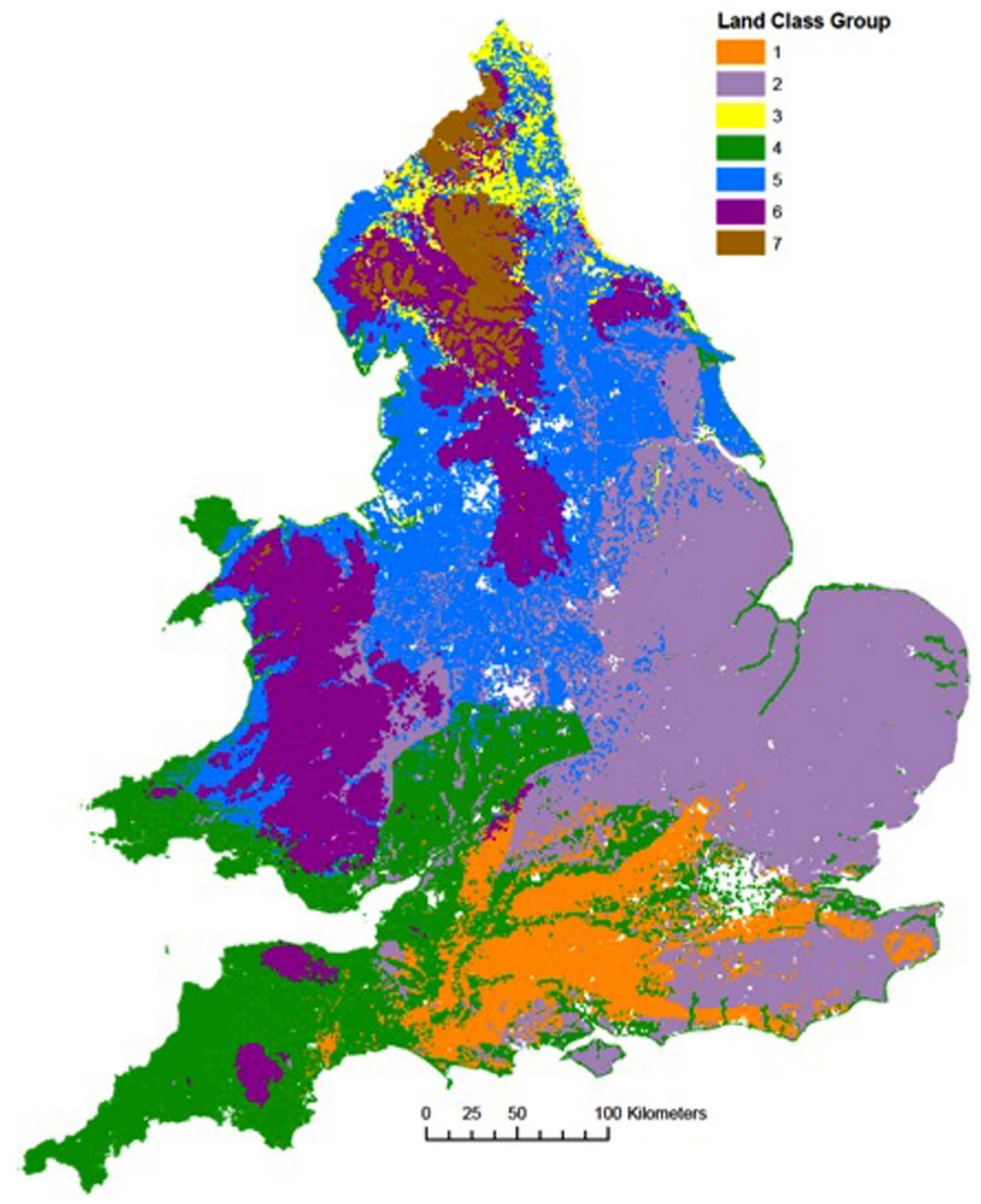

Figure $3 \mid$ Distribution of the seven Land Class Groups in England and Wales. Urban areas are not coloured. Map created in ESRI ArcGIS 10.1.

data to predict whether the increase in estimated social group abundance observed here is ongoing.

We cannot ascribe the observed changes in estimated badger social group abundance over the $\sim 25$ years to 2013 to specific factors with any degree of certainty. However, in common with the conclusions of the previous badger survey ${ }^{13}$, it seems likely to be the ongoing result of species protection and changes in habitat quality. Further analyses may reveal correlations between land management and change in social group density, but cause and effect is not likely to be firmly established.

Other carnivores living in Britain have increased their populations over similar periods. Increases in the numbers of red foxes Vulpes vulpes shot by gamekeepers are apparent from the National Gamebag Census $^{24}$, which indicates an increase of 97\% in England and 67\% in Wales between 1984-2009, with particularly marked increases of $112 \%$ in what that scheme refers to as the "easterly lowlands" of
England and Wales and $86 \%$ in the "westerly lowlands" of England and Wales. Polecat Mustela putorius gamebag records exhibited a 72\% increase from 1984-2009 in the easterly lowlands but a $39 \%$ decrease in the westerly lowlands ${ }^{24}$, though the utility of these records may be compromised by species protection and consequent underreporting of captures. Otter Lutra lutra surveys in England in 1977-79 recorded their presence in 170 of 2940 sites (5.8\%) but this had increased 10 -fold to $58.8 \%$ by $2009-10^{25}$.

The implications of increasing badger populations are numerous. Badgers are the largest terrestrial carnivore in the British Isles. They feed across numerous trophic levels, and largely eat soil invertebrates, but will also prey upon ground nesting birds, hedgehogs and other vertebrates ${ }^{8,22}$. Evaluation of the ecological impact of badger culling during the Randomised Badger Culling Trial identified an increase in fox abundance associated with reductions in badger density $^{26}$ while reciprocal relationships between hedgehog Erinaceus 


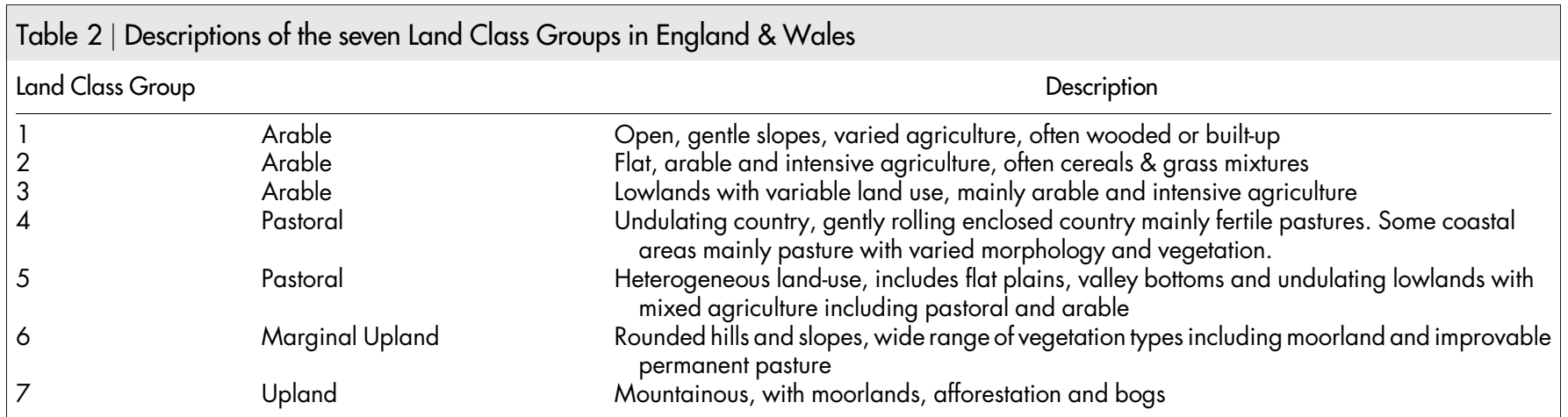

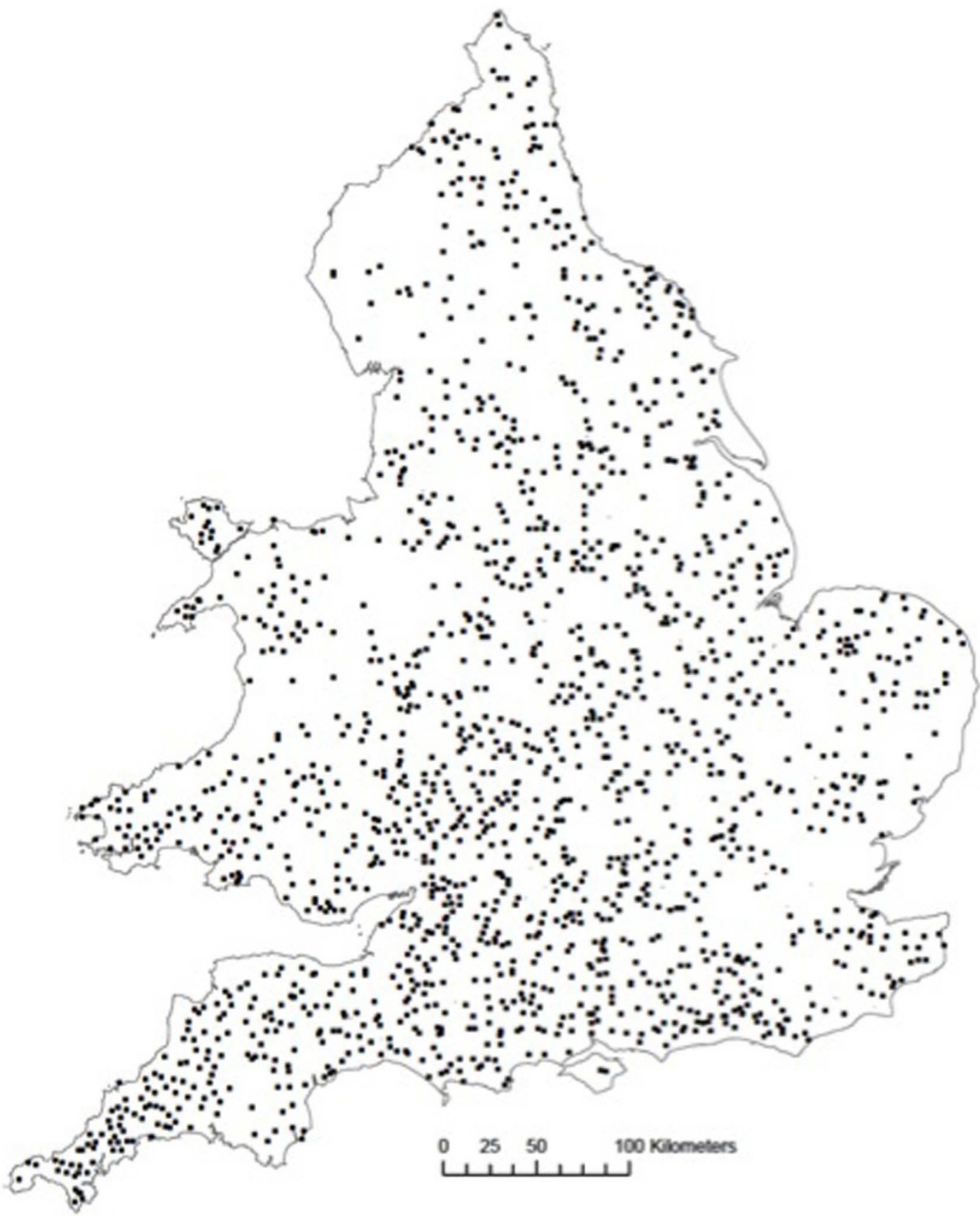

Figure $4 \mid$ Distribution of surveyed 1 km squares in England and Wales. Map created in ESRI ArcGIS 10.1. 
europaeus and badger distributions suggest that increasing badger numbers might have had a negative impact on hedgehogs ${ }^{27}$. In terms of tuberculosis epidemiology, at a local level, disease prevalence and incidence appears to vary with mobility among groups ${ }^{28}$ and prevalence has been shown to be higher in smaller social groups ${ }^{29}$. Consequently, despite a broad landscape scale correlation between the incidence of TB in cattle and the distribution of badgers ${ }^{30}$, badger social group density alone may not predict patterns of TB infection in badgers or cattle.

\section{Methods}

Sampling design. As in both previous national surveys, sampling was based on the Institute of Terrestrial Ecology (now Centre for Ecology and Hydrology) Land Classification System ${ }^{11}$. The distribution of the seven Land Class Groups is shown in Figure 3 and a basic description provided in Table 2 . We selected new survey squares (Figure 4) using a disproportionate stratified random sampling method to obtain a representative sample of the landscape in England and Wales while concentrating sampling effort on strata with greater badger density ${ }^{12,13}$ and thereby improving survey precision. See below for details of how the survey data are analysed within survey strata. Squares which contained greater than $50 \%$ urban land or water were discarded and replaced with another randomly selected square of the same land class group and general location. Therefore, in line with the previous surveys, all survey squares were predominantly rural.

Field surveys. Surveys were carried out by trained badger surveyors, all employed by the National Wildlife Management Centre, who worked to a Standard Operating Procedure. In common with the previous surveys, fieldwork was conducted in the autumn, winter and spring, when vegetation is at its lowest and badger setts are easier to find. All surveys in this study were conducted between $1^{\text {st }}$ November and $31^{\text {st }}$ March, starting in November 2011 and finishing in March 2013. No pre-existing survey information for any squares was available or provided to surveyors, so surveys were conducted "blind". All land within the $1 \mathrm{~km}$ square for which access permission had been granted was surveyed on foot. All field boundaries were surveyed initially, and badger trails (runs) radiating from the boundaries into the middle of fields were followed if there was a possibility they would lead to a sett e.g. if there was a hollow, pond, small copse etc. in the field. Rough and wooded areas and around buildings were surveyed. Surveyors walked both sides of linear features and woodland and other rough terrain was surveyed using transects. Particularly difficult terrain was surveyed by teams of staff walking in parallel within visual contact.

As with the previous two surveys, each sett found within a square was recorded on the same map and identified by a sequential number. A sett was defined as either a single hole or a series of a few or many holes. For this survey, setts were classified as either a main sett or 'other' sett. 'Other setts' combined the annex, subsidiary and outlier sett categories used in the previous two surveys ${ }^{12,13}$. Setts were classified on the basis of size, number of holes, degree of use of holes and pathways between holes and running to and from setts and the size of spoil heaps ${ }^{31}$, following the guidelines used in the previous surveys. The numbers of active, partially active and disused holes were recorded for each sett. The co-ordinates at the centre of each recorded sett were recorded using a handheld Global Positioning System (GPS).

Analysis. The survey was analysed as a set of observations in a random sample of squares stratified by LCG. The density of main setts was estimated within LCG strata from the observed number of setts and the total area surveyed in each stratum. The density across England and Wales was estimated as the mean of densities observed within each of the strata weighted by the area of each LCG within the area to which the estimate applied. Similarly, standard errors of density estimates were derived from weighted sum of within-stratum observed variances ${ }^{12}$. The proportion of squares that contained an active sett or main sett was estimated from the weighted sum of the number of squares that were found to contain a sett or main sett. Confidence intervals for densities and numbers of setts were derived assuming normally dispersed errors. Confidence intervals for proportions of squares containing a sett or main sett were estimated from a weighted random sample from modified Jeffrey's intervals for binomial proportions ${ }^{32}$.

Survey data for England and Wales from the 1985-88 badger survey of Great Britain were extracted from the survey raw data, which were accessed under license from the Joint Nature Conservation Committee and were re-analysed using the same updated LCG area estimates used in the analysis of the most recent survey to provide a baseline against which to estimate changes.

Raw survey data for the 1994-97 survey are not in the public domain. Hence, a more ad hoc analysis was undertaken. Main sett densities and LCG areas and withinstrata standard errors ${ }^{13,33}$ were used to estimate the number of main setts in Great Britain. Scottish survey results from the 1985-88 survey were inflated by a factor describing the small increase in the number of main setts observed between 1985-88 and $1994-97^{13}$. The resulting data set was analysed using the method described above to provide an estimate of the number of setts per LCG in Scotland. Finally Scottish LCG densities were subtracted from those for Great Britain, to provide an estimate of average LCG strata densities across England and Wales in the 1994-97 survey and standard errors of estimates. Densities were combined, weighted by LCG area to provide an estimate of average sett density across England and Wales. The estimate was produced chiefly for the purpose of providing an indication of whether change observed between the two more readily accessible surveys showed evidence of varying between the two time intervals examined.

1. Cassidy, A. Vermin, victims and disease: UK framings of badgers in and beyond the bovine TB controversy. Sociol. Rural. 52, 192-214; DOI:10.1111/j.14679523.2012.00562.x (2012).

2. Gortazar, C. et al. The status of tuberculosis in European wild mammals. Mammal Rev. 42, 193-206; DOI:10.1111/j.1365-2907.2011.00191.x (2012).

3. Godfray, H. C. J. et al. A restatement of the natural science evidence base relevant to the control of bovine tuberculosis in Great Britain. Proc. R. Soc. B. 280, 20131634; DOI: 10.1098/rspb.2013.1634 (2013).

4. Donnelly, C. A. et al. Impact of localized badger culling on tuberculosis incidence in British cattle. Nature 426, 834-837; DOI:10.1038/nature02192 (2003).

5. Donnelly, C. A. et al. Positive and negative effects of widespread badger culling on tuberculosis in cattle. Nature 439, 843-846; DOI:10.1038/nature04454 (2006).

6. Jenkins, H. E., Woodroffe, R. \& Donnelly, C. A. The duration of the effects of repeated widespread badger culling on cattle tuberculosis following the cessation of culling. PLOS ONE 5, e9090; DOI:10.1371/journal.pone.0009090 (2010).

7. McDonald, R. A., Delahay, R. J., Carter, S. P., Smith, G. C. \& Cheeseman, C. L. Perturbing implications of wildlife ecology for disease control. Trends Ecol. Evol. 23, 53-56; DOI:10.1016/j.tree.2007.10.011 (2008).

8. Neal, E. G. \& Cheeseman, C. L. Badgers. (London, Poyser Natural History, 1998)

9. Delahay, R. J. et al. Managing conflict between humans and wildlife: trends in licensed operations to resolve problems with badgers Meles meles in England. Mammal Rev. 39, 53-66; DOI: 10.1111/j.1365-2907.2008.00135.x (2009).

10. Page, R. Country diary: badgers are out of control. Daily Telegraph, (18 June 2013). http://www.telegraph.co.uk/earth/earthcomment/country-diary/10117911/ Country-diary-badgers-are-out-of-control.html. Downloaded 27 July 2013.

11. Bunce, R. G. H., Barr, C. J. \& Whittaker, H. A. Land classes in Great Britain: preliminary descriptions for use of the Merlewood method of land classification. (Grange-over-Sands, Institute of Terrestrial Ecology, 1981).

12. Cresswell, P., Harris, S. \& Jefferies, D. J. The history, distribution, status and habitat requirements of the badger in Britain. (Peterborough, Nature Conservancy Council, 1990).

13. Wilson, G., Harris, S. \& McLaren, G. Changes in the British badger population 1988 to 1997. (London, People's Trust for Endangered Species, 1997).

14. Rainey, E., Butler, A., Bierman, S. \& Roberts, A. M. I. Scottish Badger Distribution Survey 2006 - 2009: estimating the distribution and density of badger main setts in Scotland. (Scottish Badgers and Biomathematics and Statistics Scotland, 2009).

15. Feore, S. M. The distribution and abundance of the badger Meles meles L in Northern Ireland. (PhD thesis, Queen's University Belfast, 1994).

16. Reid, N., Etherington, T. R., Wilson, G. J., Montgomery, I. \& McDonald, R. A. Monitoring and population estimation of the European badger Meles meles in Northern Ireland. Wildlife Biol. 18, 46-57; DOI: 10.2981/11-016 (2011).

17. Wilson, G. J. \& Delahay, R. J. A review of methods to estimate the abundance of terrestrial carnivores using field signs and observation. Wildlife Res. 28, 151-164; DOI:10.1071/WR00033 (2001).

18. Lara-Romero, C., Virgos, E. \& Revilla, E. Sett density as an estimator of population density in the European badger (Meles meles). Mammal Rev. 42, 78-84; DOI:10.1111/j.1365-2907.2011.00194.x (2012).

19. Wilson, G. J., Delahay, R. J., de Leeuw, A. N. S., Spyvee, P. D. \& Handoll, D. Quantification of badger (Meles meles) sett activity as a method of predicting badger numbers. J. Zool. 259, 49-56; DOI:10.1017/S0952836902002947 (2003).

20. Delahay, R. J. et al. Long-term temporal trends and estimated transmission rates for Mycobacterium bovis infection in an undisturbed high-density badger (Meles meles) population. Epidemiol. Infect. 141, 1445-1456; DOI:10.1017/ S0950268813000721 (2013).

21. Ostler, J. R. \& Roper, T. J. Changes in size, status and distribution of badger Meles meles L. setts during a 20 year period. Z. Säugertierk. 63, 200-209 (1998).

22. Roper, T. J. Badger. (London, HarperCollins, 2010).

23. Macdonald, D. W., Newman, C., Nouvellet, P. M. \& Buesching, C. D. An analysis of Eurasian badger (Meles meles) population dynamics: Implications for regulatory mechanisms. J. Mammal. 90, 1392-1403; DOI:10.1644/08-MAMM-A356R1.1 (2009).

24. Aebischer, N. J., Davey, P. D. \& Kingdon, N. G. National Gamebag Census: Mammal Trends to 2009. (Game and Wildlife Conservation Trust, Fordingbridge, 2011) (http://www.gwct.org.uk/ngcmammals).

25. Crawford, A. Fifth Otter Survey of England 2009-2010. (Environment Agency, Bristol, 2010).

26. Trewby, I. D. et al. Experimental evidence of competitive release in sympatric carnivores. Biol. Lett. 4, 170-172; DOI:10.1098/rsbl.2007.0516 (2008).

27. Young, R. P. et al. Abundance of hedgehogs (Erinaceus europaeus) in relation to the density and distribution of badgers (Meles meles). J. Zool. 266, 81-87; DOI:10.1111/j.1469-7998.2006.00078.x (2006).

28. Vicente, J., Delahay, R. J., Walker, N. J. \& Cheeseman, C. L. Social organization and movement influence the incidence of bovine tuberculosis in an undisturbed high-density badger Meles meles population. J. Anim. Ecol. 76, 348-360; DOI:10.1111/j.1365-2656.2006.01199.x (2007). 
29. Woodroffe, R. et al. Social group size affects Mycobacterium bovis infection in European badgers (Meles meles). J. Anim. Ecol. 78, 818-827; DOI:10.1111/j.13652656.2009.01545.x (2009).

30. Wilesmith, J. W. Epidemiological features of bovine tuberculosis in cattle herds in Great Britain. J. Hyg-Cambridge 90, 159-176 (1983).

31. Kruuk, H. Spatial organization and territorial behavior of the European badger Meles meles. J. Zool. 184, 1-19; DOI:10.1111/j.1469-7998.1978.tb03262.x (1978).

32. Brown, L. D. et al. Interval estimation for a binomial proportion. Stat. Sci. 16, 101-133 (2001).

33. Wilson, G. J. Patterns of Population Change in the Eurasian Badger (Meles meles) in Britain, 1988 - 1997. (PhD Thesis, University of Bristol, 1998).

\section{Acknowledgments}

We are grateful to the thousands of landowners for their kind co-operation in granting access to their land. This study was funded by the Department for Environment, Food and Rural Affairs, as part of England and Wales national research activities. Fieldwork was conducted by staff of the National Wildlife Management Centre. Access to data from the
1985-88 survey was licensed by the Joint Nature Conservation Committee, to whom the rights of the Nature Conservancy Council had passed.

\section{Author contributions}

The project was designed by J.J., G.J.W., R.A.M. and R.M. and run by J.J. R.M. analysed the data. The paper was written by J.J., G.J.W., R.M., R.J.D. and R.A.M.

\section{Additional information}

Competing financial interests: The authors declare no competing financial interests.

How to cite this article: Judge, J., Wilson, G.J., Macarthur, R., Delahay, R.J. \& McDonald, R.A. Density and abundance of badger social groups in England and Wales in 2011-2013. Sci. Rep. 4, 3809; DOI:10.1038/srep03809 (2014).

(c) (i) $($ This work is licensed under a Creative Commons AttributionBY No NonCommercial-NoDerivs 3.0 Unported license. To view a copy of this license, visit http://creativecommons.org/licenses/by-nc-nd/3.0 